\title{
From the notch to a glioma grading system: the neurological contributions of James Watson Kernohan
}

\author{
Sam Safavi-Abbasi, M.D., Ph.D., ${ }^{1}$ Adrian J. Maurer, M.D., ${ }^{1}$ Jacob B. Archer, M.S., ${ }^{1}$ \\ Ricardo A. Hanel, M.D., Ph.D., ${ }^{2}$ Michael E. Sughrue, M.D., ${ }^{1}$ \\ Nicholas Theodore, M.D., ${ }^{3}$ and Mark C. Preul, M.D. ${ }^{3}$ \\ ${ }^{1}$ Department of Neurosurgery, University of Oklahoma Health Science Center, Oklahoma City, Oklahoma; \\ ${ }^{2}$ Department of Neurosurgery, Mayo Clinic, Jacksonville, Florida; and ${ }^{3}$ Division of Neurological Surgery, \\ Barrow Neurological Institute, St. Joseph's Hospital and Medical Center, Phoenix, Arizona
}

\begin{abstract}
During his lifetime and a career spanning 42 years, James Watson Kernohan made numerous contributions to neuropathology, neurology, and neurosurgery. One of these, the phenomenon of ipsilateral, false localizing signs caused by compression of the contralateral cerebral peduncle against the tentorial edge, has widely become known as "Kernohan's notch" and continues to bear his name. The other is a grading system for gliomas from a neurosurgical viewpoint that continues to be relevant for grading of glial tumors 60 years after its introduction. In this paper, the authors analyze these two major contributions in detail within the context of Kernohan's career and explore how they contributed to the development of neurosurgical procedures.

(http://thejns.org/doi/abs/10.3171/2014.1.FOCUS13575)
\end{abstract}

KEY WoRds • craniotomy • glial tumor • grading system

$\mathrm{D}$ URING his lifetime and a career spanning 42 years at the Mayo Clinic (from 1922 to 1961) and at the Barrow Neurological Institute (from 1962 to 1964), James Watson Kernohan made numerous contributions to general pathology, neuropathology, neurology, and neurosurgery. However, there are two topics that represent especially enduring contributions that are significant to neurosurgery and the neurosurgical history of craniotomy. One continues to bear his name, ${ }^{12}$ and the other is a grading system for gliomas geared toward a neurosurgical viewpoint that continues to be relevant for the grading of glial tumors 60 years after its introduction. In this paper, we analyze these two major contributions in detail within the context of Kernohan's career and explore how they contributed to the development of neurosurgical craniotomy procedures.

\section{Early Life and Transition to the Mayo Clinic}

A schoolteacher's son, Kernohan was born in Moyasset, County Antrim, North Ireland, on October 1, 1896. Kernohan was one of three children. He completed his medical training at Queen's University in Belfast (Fig. 1), in 1920, where he received bachelor's degrees in medicine (M.B.), surgery (B.Ch.), and obstetrics (B.A.O.). Subsequently he also earned a Diploma in Public Health (D.P.H.) and a bachelor of science (B.Sc.) degree in 1921, also from Queen's. Following his medical training, Kernohan spent 1 year at the Crichton Royal Institution in
Dumfries, Scotland (Fig. 2), as a clinical pathologist ${ }^{3}$ and subsequently left for the United States in 1922 to become a fellow in pathology at the Mayo Graduate School of Medicine in Minnesota, which at that time was already one of the leading centers for pathology worldwide. The fellowship also gave him an opportunity to train in the Department of Pathology at the University of Minnesota, from which he earned a master's degree (M.A.) in anatomy and pathology in 1924. The thesis of his master's degree was The Ventriculus Terminalis: Its Growth and Development. Through his dissertation on this ependymal-lined space within the conus medullaris, he became interested in ependymomas of the spinal cord, which led to his interest in nervous system tumors in general. ${ }^{4,8,10,26}$

In 1925, Kernohan joined the Section of Anatomical Pathology at the Mayo Clinic, which was headed by H. E. Robertson. Robertson, described by contemporaries as a dynamic and forceful personality, was uninterested in neuropathology and gladly turned over that more specialized field to his young colleague. ${ }^{26}$ Thus, while he remained active in general pathology and published papers on hypertension and systemic vascular disease through the latter half of the 1920s, he progressively transitioned to neuropathological investigation.

In 1932, Kernohan married Eleanor Fletcher of Winnipeg, a former fellow in pathology. One of the characteristics of his personality was his ability to collaborate broadly with colleagues from other fields. This ability was reflected in his early collaborations with clinicians 


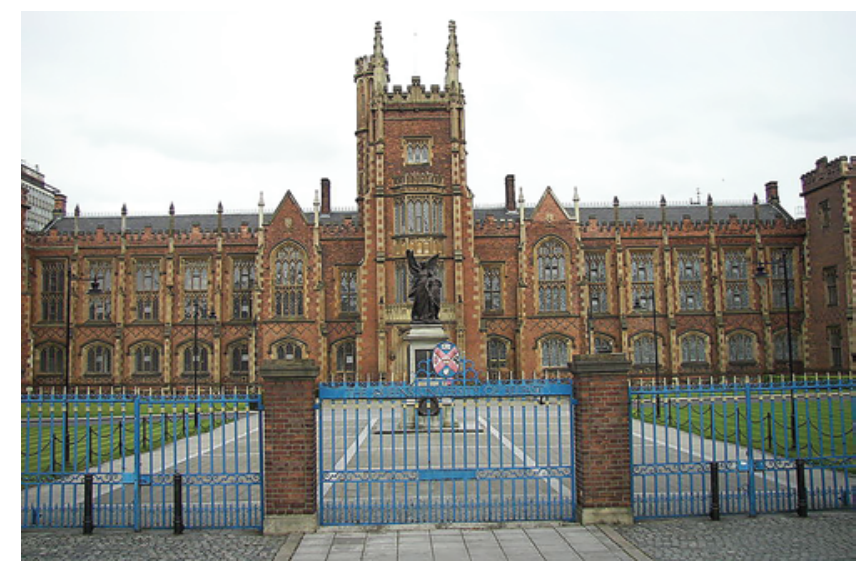

FIG. 1. The Queens University, Belfast, where Kernohan completed his medical training.

from the fields of neurology and neurosurgery. By 1931, Kernohan had coauthored his first article on spinal tumors, the first among many on this subject. ${ }^{3,26} \mathrm{He}$ described common manifestations of a variety of spinal extradural tumors, including lymphoma, myeloma, and metastatic carcinoma. ${ }^{8,10}$ An interesting article published in 1935 reflects both his ability to broadly collaborate and his in-depth interest in neuropathology. In this article entitled "A glioma in a dog and a pinealoma in a silver fox," he wrote of performing necropsy and offered a detailed histopathological evaluation of a Boston terrier dog that was found to have a large invasive tumor that Kernohan classified as glioblastoma multiforme. He stated "this neoplasm belongs to the glioma group of the nervous sys- tem... and is encountered not uncommonly in human beings." In this publication he also described the first case of a pineal tumor in an animal. ${ }^{27}$

At the Mayo Clinic, Kernohan also worked closely with Henry W. Woltman, a renowned neurology and neuropathology professor who founded the American Board of Psychiatry and Neurology and later became the head of the Section of Neurology and Psychiatry at the Mayo Clinic. When Woltman died in 1964, Kernohan wrote of his collaborator, "[he was] one with "standards not accessible to ordinary men', a man dedicated to perfection in all he did, and as a worker who cared nothing for personal rewards." " During this time at the Mayo Clinic, they would publish several articles together, among which was his well-known paper on the notching of the crus cerebri by the free tentorium, a phenomenon later becoming widely known as "Kernohan's notch."

\section{The "Notch"}

At a time when imaging modalities were limited, physicians largely relied on the clinical examination and physical signs to determine the location and probable nature of the pathological process. Several physicians became interested in the localizing nature of the signs and symptoms of increased intracranial pressure. ${ }^{22,28}$ James Stansfield Collier (1870-1935), an assistant physician at the St. George's Hospital and The National Hospital for Nervous Disease, reported his observations of 161 patients with brain lesions presenting with "false localizing signs" during the years 1894-1904 while he was working with the renowned neurologists John Hughlings Jackson

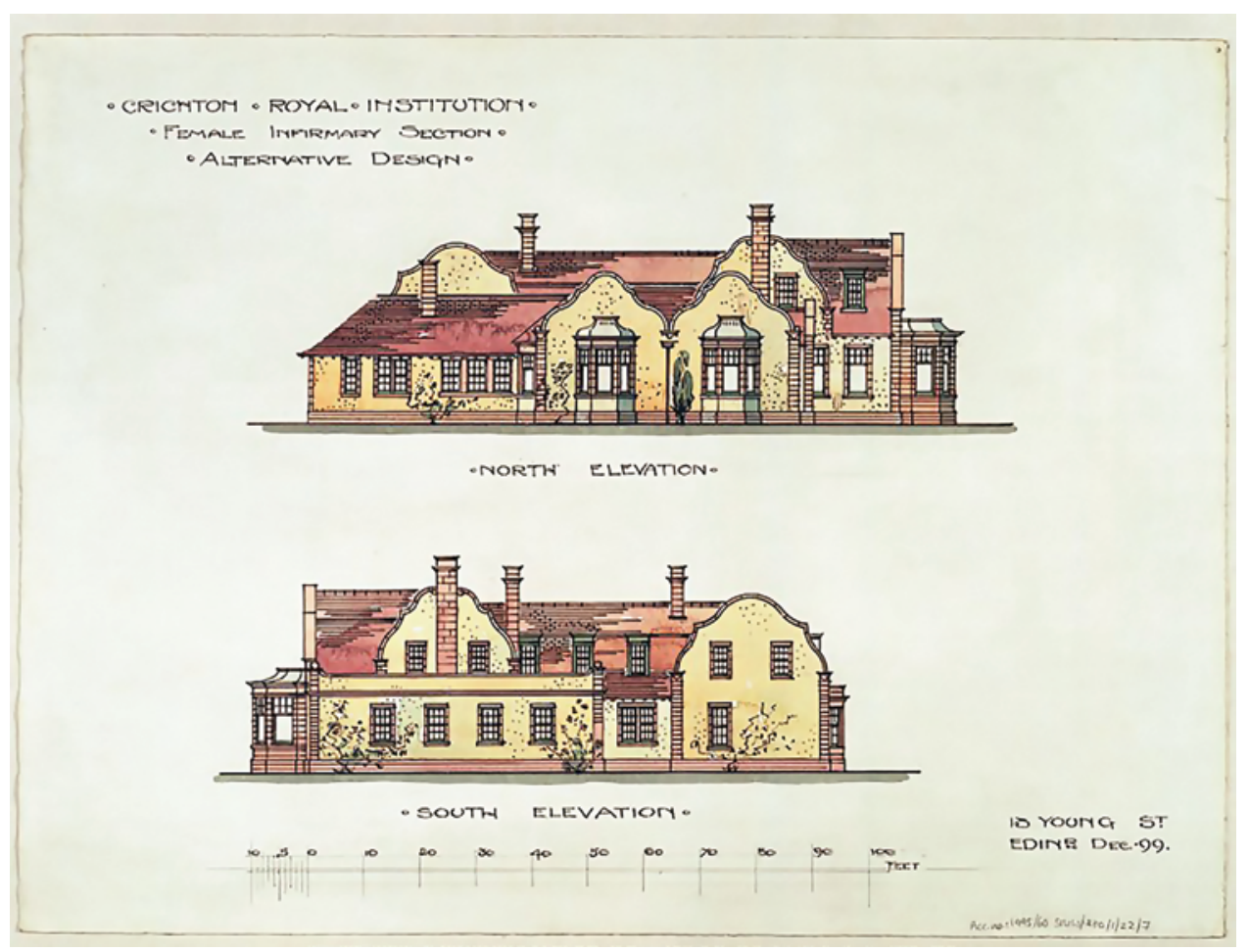

FIG. 2. The Crichton Royal Institution in Dumfries, Scotland, where Kernohan spent 1 year as a clinical pathologist before migrating to the United States. Copyright RCAHMS (Sydney Mitchell and Wilson Collection). Licensor www.rcahms.gov.uk. 


\section{Contributions of James Watson Kernohan}

and Gordon Holmes. ${ }^{6}$ Collier observed false localizing signs in $20(12.4 \%)$ of the 161 consecutive cases examined clinically and pathologically. In autopsy studies, Collier elaborated that

in many cases of supratentorial tumours the tentorium is pressed downwards. The medulla and posterior part of the cerebellum come to lie partly within the foramen magnum so that these structures together form a conical plug which fills up foramen magnum. This alteration in the position of the brain may be also demonstrated post mortem by deep indentation of the crura cerebri by the free edge of the tentorium. ${ }^{6}$

Collier also described the case of a 39-year-old patient who "...was admitted on July 16, 1900, under the care of Hughlings Jackson. He had suffered headache and vomiting for two months, and he presented well marked optic neuritis." The patient developed seizures, aphasia, and progressive paralysis of the right arm and face. A left-sided lesion was therefore suspected, and the patient then underwent surgery; as described by Collier, "an exploratory craniotomy in the left fronto-central region revealed an extensive softening. Subsequently necropsy showed that a large tumour was situated on the right optic thalamus, and that the anterior branches of the left sylvian artery were extensively thrombosed." These findings were reinforced a year later when Louis Alquier reported similar findings in autopsy studies. ${ }^{28}$ Alquier hypothesized that the brain tissue "is forced to migrate due to pressure effect of the tumor."

In 1920, Adolf Meyer gave a well-illustrated pathological presentation at the 46th Annual Meeting of the American Neurological Association in New York on "Herniation of the brain." ${ }^{21}$ Meyer concluded, "Herniation in brain tumor and brain swelling occurs under the falx, under the tentorium and into the foramen magnum." ${ }^{21}$ Furthermore, he made the important observation that "the falx and tentorium constitute an important protection against any sudden impacts of pressure by keeping apart heavy portions of the brain, but they also provide an opportunity for trouble in case of swelling or need of displacement."

In 1927, Groeneveld and Schaltenbrand reported a case involving a lesion of the left sylvian fissure and production of a notch in the pes pedunculi with pressure on the tentorial edge. ${ }^{11}$ The article described a 43-year-old man who presented with Jacksonian seizures and spastic hemiparesis on the left side. At autopsy, a tumor was found near the left sylvian fissure that had displaced the brain toward the right, resulting in stretching of the internal capsule and production of a pressure notch in the pes pedunculi by the free edge of the tentorium. The authors concluded that the pressure point was responsible for ipsilateral hemiparesis. ${ }^{11}$

A year later, in 1928, Kernohan and Woltman published their first case report on the "Incisura of the crus due to contralateral brain tumor" in the of Proceedings of The Staff Meetings of the Mayo Clinic, ${ }^{18}$ and subsequently in 1929 they published a more detailed account with evaluations of clinical and pathological data of various patients treated at the Mayo Clinic. ${ }^{17}$ In their detailed review of the literature, they mention the articles by Meyer and give a thorough translation and review of the case reported by Groeneveld and Schaltenbrand. Interesting- ly, however, the publication by Collier is not mentioned in their article. In their 1929 article, they evaluated 276 brains at autopsy (Fig. 3), excluding cases with midline lesions and metastatic disease "to reduce the possibility of direct pressure to the opposite pyramidal tract by the tumor itself." They described "notching" in 42 patients, of whom 7 had marked clinical ipsilateral pyramidal signs (prior to death as determined by subsequent chart review), 17 had slight ipsilateral/false localizing signs ( 2 without notching), and 18 had no clinical signs but did have notching (Fig. 4). To explain this they wrote:

In eighteen cases more or less notching was not found; in these a survey of the corresponding histories did not disclose the presence of homolateral signs of the pyramidal tract on which we based our selection. In five of these cases, however, tendon reflexes were active on the same side as the lesion. For the remaining discrepancies, we do not have an adequate explanation..$^{17}$

In the abstract of the discussion, Kernohan and Woltman proposed the possibility of vascular injury as a cause as opposed to a mechanical cause. However, they wrote: "It was necessary to remove the posterior cerebral and other subarachnoid arteries in this region (in autopsy) to see the notch...the grooves did not seem to be the result of arterial compression and none of the vessels was thrombosed." 17 This continues to be matter of debate, especially since almost half $(n=17)$ of the patients in their highly selective cohort showed only slight degree of ipsilateral signs, 2 without notching (on autopsy); moreover, 18 patients had notching without clinical ipsilateral (false localizing) signs, and only 7 patients had marked ipsilateral pyramidal signs. ${ }^{9,13}$ Nevertheless, the phenomenon of ipsilateral/false localizing symptoms caused by compression of the contralateral cerebral peduncle against the tentorial edge has widely become known as "KernohanWoltman phenomenon," "Kernohan's notch phenomenon," or "Kernohan's notch,", ${ }^{13,22,33}$ and this phenomenon

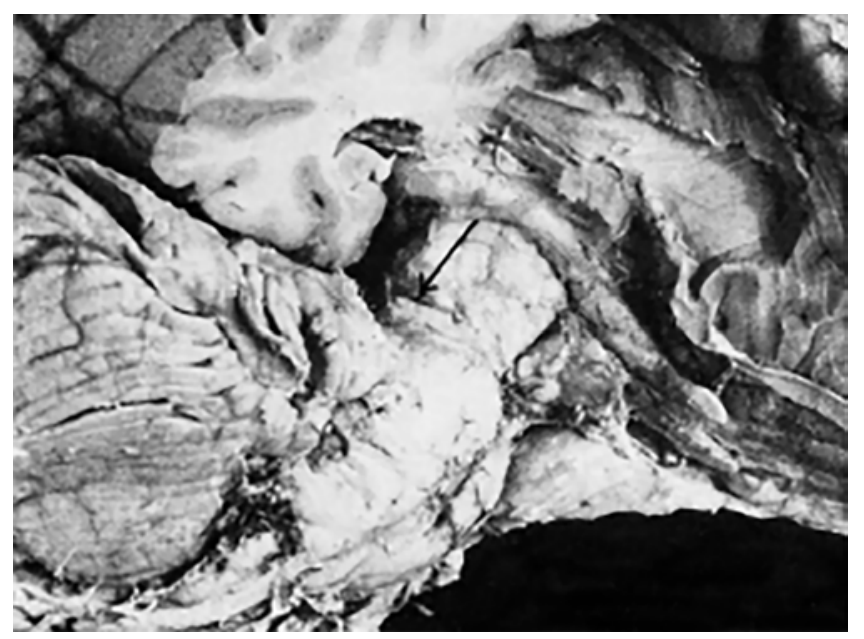

FIG. 3. Original photograph showing a pathological postmortem specimen of an abscess in the left parietotemporal lobe. A groove in the right peduncle (arrow) indicates "notching" of the cerebral peduncle. Reprinted with permission from Kernohan JW, Woltman HW: Incisura of the crus due to contralateral brain tumor. Arch Neurol Psychiatry 21: 274-287, 1929. Copyright @ 1929 American Medical Association. All rights reserved. 


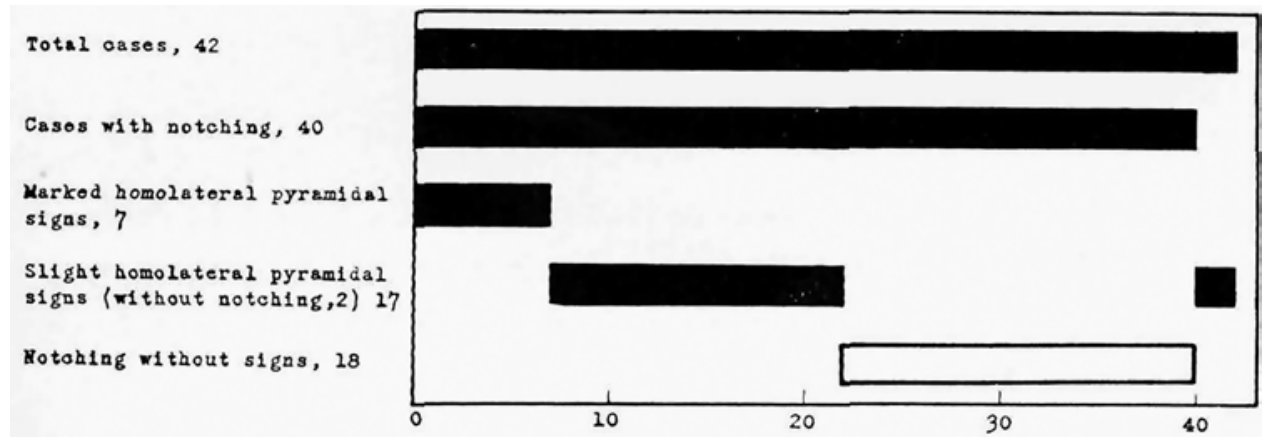

FIG. 4. Original graph from the 1929 "notch" paper. The graph indicates "notching" in a total of 42 patients, of whom only 7 had marked clinical homolateral pyramidal signs, 17 had slight homolateral localizing signs (2 without notching), and 18 had no clinical signs but did have notching. This indicates that almost half of the patients did not have clinical signs related to pressure on the cerebral peduncle. Reprinted with permission from Kernohan JW, Woltman HW: Incisura of the crus due to contralateral brain tumor. Arch Neurol Psychiatry 21:274-287, 1929. Copyright @ 1929 American Medical Association. All rights reserved.

continues to lead to confusion and clinical misdiagnosis resulting in wrong-side craniotomy in spite of modern imaging technology. ${ }^{31}$ More recently, imaging techniques and electrophysiological findings have been used to demonstrate compression or structural damage to the cerebral peduncle contralateral to a supratentorial lesion, providing a radiological correlate. ${ }^{5,13,33}$ There is considerable individual anatomical variation in the tentorial notch, and it is thought that morphometric variations in the tentorial aperture and its regional anatomy may be implicated the different clinical presentations. ${ }^{2,5,29}$ It is unknown to what degree the notch phenomenon guided surgical decisions at the Mayo Clinic or if the sign could be overtly linked to guiding craniotomies. Given the influence of Kernohan upon neurosurgeons at the Mayo department, evaluation of the associated clinical signs is likely to have been incorporated into education and assessment of the critically ill patient.

\section{A Simple Glioma Grading System}

Kernohan continued his prolific academic career at Mayo Clinic, collaborating with Woltman and the neurosurgeon Alfred W. Adson (Fig. 5) on many publications. Beginning in 1931, the group published several papers on spinal cord tumors, and in 1948 they published a landmark paper entitled "Gliomas of the cerebellopontine angle," including a 10-patient case series (the largest series on the topic at that time).${ }^{19}$ Reflecting on his previously performed dissertation work, he stated, “...this lateral medullary velum is a narrow band of tissue...this lamina of tissue reminds us very much of the histologic structure of the filum terminale. We have found that the majority of tumors of the filum terminale are ependymomas. In our study of gliomas arising from the lateral medullary velum of the fourth ventricle we have found that 80 per cent of the gliomas were of ependymal type."19 Additionally, Kernohan became the acting head of the Mayo Clinic Section of Surgical Pathology in 1935, where he became well versed in various diagnostic and prognostic tumorgrading scales. Although this new position kept Kernohan busy and intellectually stimulated, he continued to contribute heavily to the literature and advance the field of neuropathology.
In 1949, Kernohan published a paper on a simplified 4-grade classification of gliomas in the Proceedings of The Staff Meetings of the Mayo Clinic, ${ }^{15}$ and in the same year, he and Adson, together with their colleagues, published a second, more detailed paper applying their classification. ${ }^{30}$ The conventional system used to grade brain tumors at this time was Bailey and Cushing's classification, which accentuated similarities of glial neoplasms to cells in various phases of embryological development. ${ }^{4}$ They proposed a

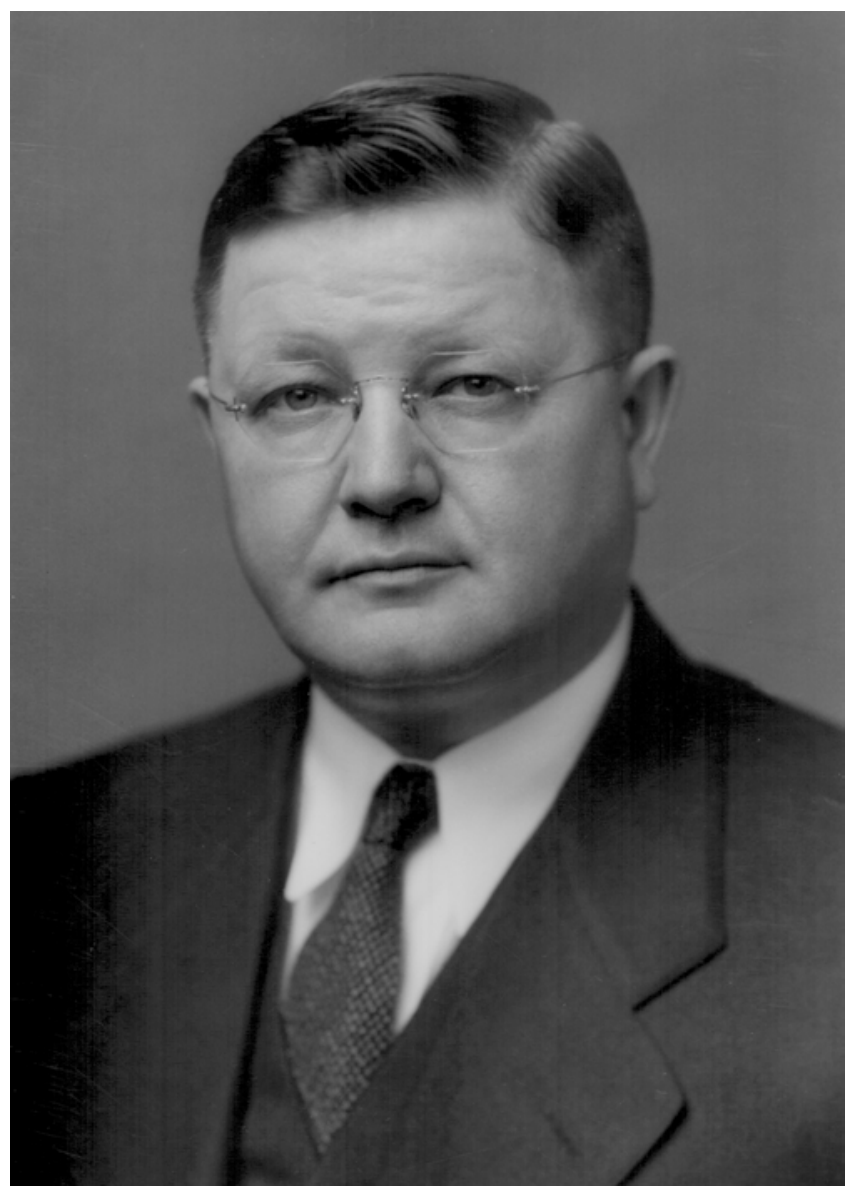

FIg. 5. Mayo Clinic neurosurgeon Alfred W. Adson. Used with permission from Hennepin County Library Special Collections. 


\section{Contributions of James Watson Kernohan}

3-tier system of astrocytoma, astroblastoma, and spongioblastoma multiforme (glioblastoma multiforme), with up to 17 subdivisions dispersed among the tiers.

In their publication, Kernohan and colleagues stated, "a simplification of the present classification of gliomas together with the grading of the degree of malignancy within each group would be highly advantageous to the neurosurgeon." They further indicated that "the grouping of tumors called astroblastoma has been severely criticized on the grounds that the limits are ill-defined and artificial. In defining this subgroup, Bailey and Cushing did not adhere strictly to histogenetic dicta." Kernohan and colleagues therefore introduced their 4-tiered system based on degree of anaplastic transformation, mitotic figures, and vascularity. Importantly, the system considered the percentage of "normal-appearing" neoplastic astrocytes in the specimen, as opposed to the Bailey-Cushing model which based the tumor grade on the most malignant areas of the specimen without considering the welldifferentiated elements. They stated: "In our group of astrocytomas graded 1 to 4 on the degree of malignancy, we have included the following glioma subdivisions of Bailey and Cushing: astrocytoma, polar spongioblastoma, astroblastoma and glioblastoma multiforme."

Kernohan applied this system to astrocytomas and ependymomas and stated that the classification could also be applied to oligodendrogliomas. However, he did not have a big enough sample of this histological subtype to make any conclusions:

We have not yet studied oligodendrogliomas with the object in view of classifying them according to different grades of malignancies we have done with astrocytomas and ependymomas. Our series of oligodendrogliomas is not sufficiently large to be statistically significant. It is well known by neurosurgeons and neuropathologists that most oligodendrogliomas grow very slowly, but it is also well known that some are highly malignant and grow rapidly. ${ }^{30}$

Shortly after the introduction of the Kernohan system, the Swedish pathologist Nils Ringertz, who later became the Secretary General for the Nobel Prize Committee, presented his 3-tiered classification system in the same year. ${ }^{24}$ He stated, "In a paper read before the meeting of the Nordish Neuro-Surgeons in September 1946 (unfortunately not printed), the author presented a comparison of the histopathology and the postoperative prognosis of the different types of glioma." His system included astrocytomas, ependymomas, and oligodendrogliomas. Ringertz further indicated, "whichever system is used, a four-step or a three-step system as suggested by me, the figures reflecting the life history of the tumors will plainly evidence that there exists a gradual transition in biologic properties from the most benign to the most malignant of these neoplasms....It is more or less a matter of taste which of the grading systems is selected."

Thus, in both classification systems the tumor was related to a normal cell type that it resembled the most and from which it was supposedly derived; additionally, the degree of malignancy or histological findings considered to indicate anaplasia were estimated on a scale from least to greatest for the tumor as a whole. These classification systems were both adapted worldwide as Ringertz suggested, and became a matter of some controversy and confusion; nevertheless, they are the basis for the modern glioma classification systems. ${ }^{20,23,25,32}$

The system introduced by Kernohan and colleagues continues to bear relevance to the understanding of clinical and biological features of gliomas. In their landmark publication, they found that with increasing histological grade, there was an increase in the mean age of the patient, decrease in the duration of preoperative symptoms, and a diminution in the mean postoperative survival. ${ }^{15,30}$ These are features that Kernohan in collaboration with Adson identified, and from a neurosurgical perspective, they were (and continue to be) extremely important since they integrate the histopathological tumor grade with postoperative survival. Both classifications provided prognostically and clinically useful subclassifications because tumor grade was linked to outcome, in which lower grades reflect better outcomes and higher grades reflect shorter survival. The validity of the 4-tier versus the 3-tier system was a matter of controversy after their introduction. Historically, the grading systems of Kernohan and Ringertz prevailed; however, today the WHO classification is more widely accepted and has replaced the older classifications..$^{20,23,32}$ Because of the confusion that had arisen as a consequence of the differences in the classification schemes, the WHO created a committee of international experts to develop a system that incorporated the most creditable aspects of different classifications. ${ }^{32}$ As a result of intensive discussions, a system was produced and published as monograph in $1986 . .^{32}$

\section{Retirement and Final Years}

Kernohan succeeded Robertson as the head of the Section of Anatomical Pathology at the Mayo Clinic from 1943 to $1955,{ }^{8,10}$ and in 1952 he was elected president of the staff of the Mayo Clinic, a position he held until his retirement in 1962 (Fig. 6). After his retirement, Kernohan became a consultant at the Barrow Neurological Institute in Phoenix, Arizona, from 1962 to 1964. For the remainder of his career at the Mayo Clinic and as founding Chairman of the Division of Neuropathology at the Barrow Neurological Institute, he continued writing prolifically. He continued to study some of the lesions that were not easily classified in his 1948 landmark paper, identifying one group as sarcomas of the brain. ${ }^{1}$ He reclassified some previously undesignated specimens as sarcomas of the brain using this system. These findings were published during the 1960s and included in his monograph on sarcomas of the brain, coauthored with the Mayo Clinic neurosurgeon Alfred Uihlein (Fig. 7) in 1965. ${ }^{16} \mathrm{He}$ also published these findings in a series of papers from 1960 to $1969 .{ }^{14,16}$ Additionally, he continued his interest in varied aspects of neuropathology and general pathology, amassing nearly 200 individual publications in his lifetime. With his ability to collaborate with his colleagues in neurology and neurosurgery, the pathologist and neuropathologist Kernohan was able to make significant contributions to all fields of the neurosciences.

Kernohan held several prominent positions within the societies of pathology, neuropathology, and neurology. In 1938 and 1939, he was president of the American 


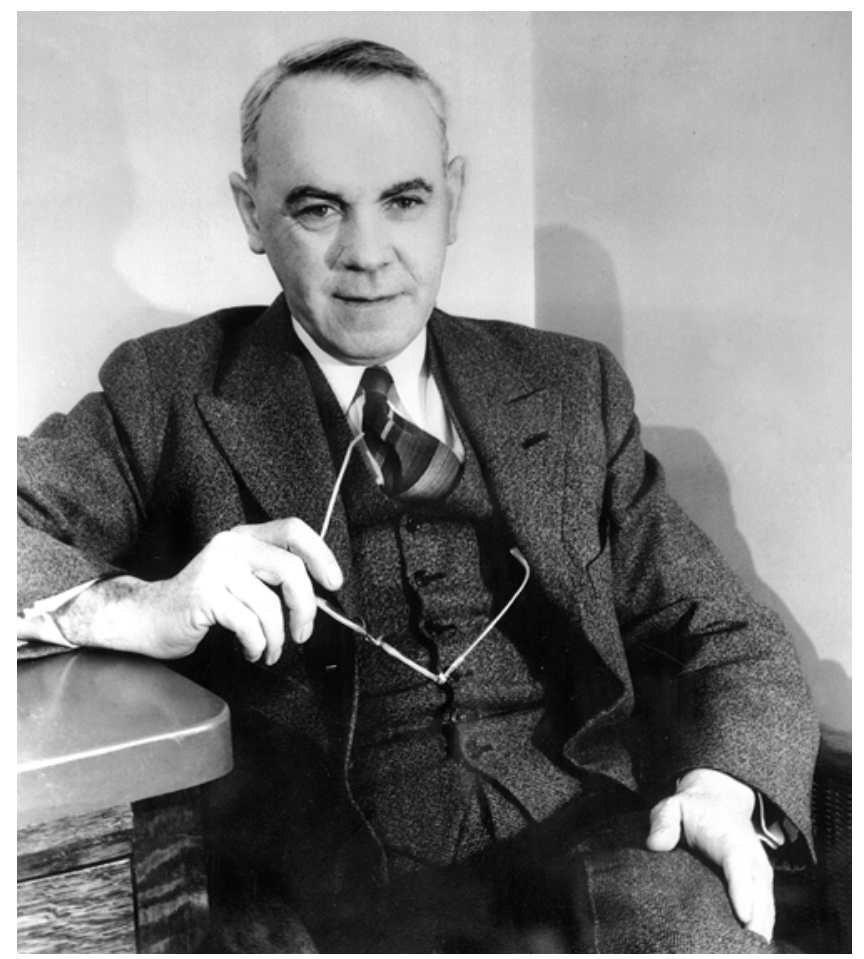

FIG. 6. Dr. Kernohan during his tenure at the Mayo Clinic. Used with permission of the Mayo Foundation for Medical Education and Research. All rights reserved.

Association of Neuropathologists and was appointed the vice president of the American Neurological Association in 1955. He was a member of the American Board of Pathology from 1946 to 1960 , serving as the president from 1957 to 1959. During his time on the American Board of Pathology, Kernohan made significant strides toward the establishment of subspecialty certification in neuropathology. He also served as chairman of the Scientific Advisory Board of the Armed Forces Institute of Pathology in 1954. ${ }^{4,10,26}$ For his contributions to science, in 1966, he was accorded an honorary degree of Doctor of Science from Queen's University, where he started his medical work. At the dinner ceremony before receiving the honorary degree, he was seated between the other two candidates, the Anglican Archbishop of Armagh and the Anglican Primate of All Ireland and the Cardinal Archbishop of Armagh and Roman Catholic Primate of All Ireland. ${ }^{4}$ Kernohan was also presented with the award for Meritorious Contributions to Neuropathology by the American Association of Neuropathologists in 1971; the plaque for this award reads "in grateful recognition of his dedication and contribution to Neuropathology." An avid golfer since his youth in Ireland, during his time at the Barrow Neurological Institute in Phoenix, Kernohan was able to combine neuropathology regularly and throughout the year with his golf. ${ }^{4} \mathrm{He}$ also golfed and formed a friendship with the Mayo brothers in Rochester. ${ }^{3}$ Following retirement, he returned to his home in Rochester, Minnesota, where he continued to publish on neuropathology into the 1970s. He died on May 5, 1981, at the age of 84 in Rochester, Minnesota. His wife survived him in addition to one daughter. ${ }^{26}$

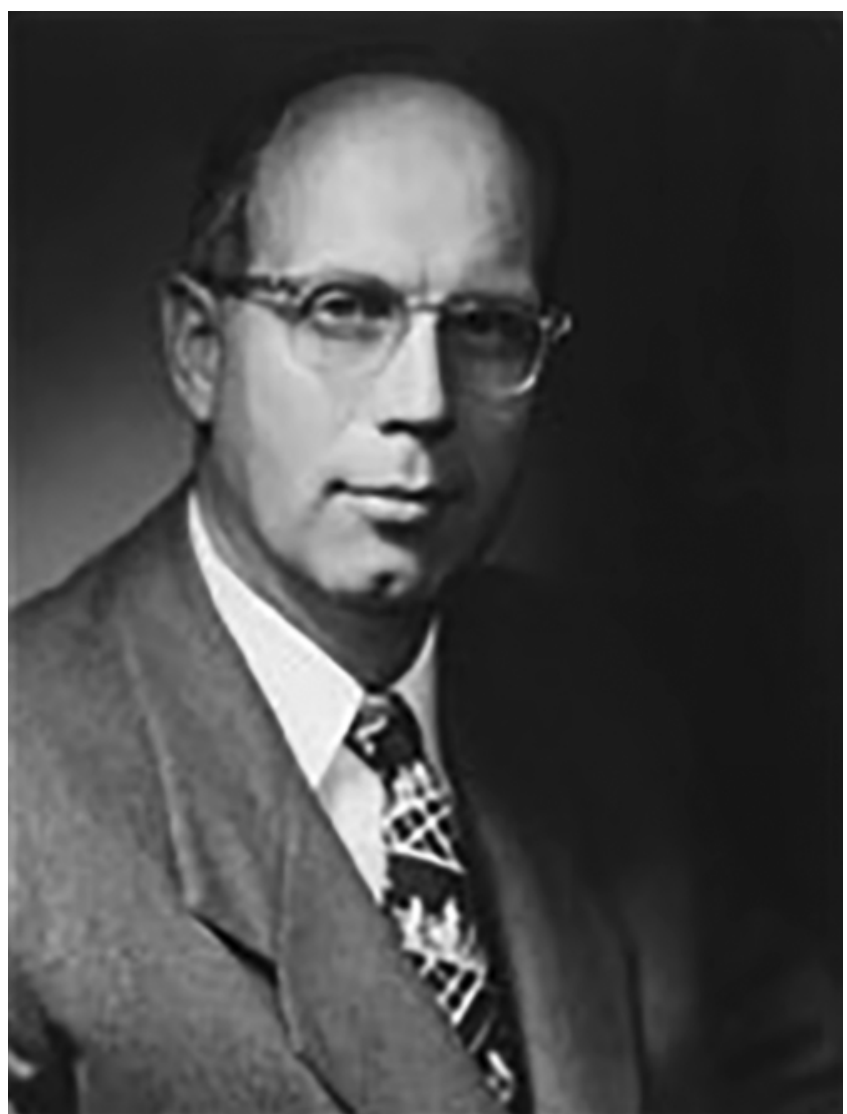

FIG. 7. Mayo Clinic neurosurgeon Alfred Uihlein. Used with permission from the Society of Neurological Surgeons.

\section{Conclusions}

During his lifetime and a career spanning 42 years, James Watson Kernohan through his friendship and collaborations made numerous contributions to general pathology, neuropathology, neurology, and neurosurgery. Two of his contributions were especially enduring and significant to neurosurgery and the neurosurgical history of craniotomy. Together with the neurologist Henry Woltman, he popularized the recognition of a false localizing sign produced by "notching" of the crus cerebri by the free tentorium, a phenomenon later becoming widely known as Kernohan's notch. He also introduced a simple grading system for gliomas that was geared toward a more neurosurgical viewpoint and that continues to be relevant to this date.

\section{Disclosure}

The authors report no conflict of interest concerning the materials or methods used in this study or the findings specified in this paper.

Author contributions to the study and manuscript preparation include the following. Conception and design: Preul, Safavi-Abbasi, Theodore. Acquisition of data: Safavi-Abbasi, Maurer, Archer. Drafting the article: Safavi-Abbasi, Maurer, Archer. Critically revising the article: Preul, Safavi-Abbasi, Maurer, Hanel, Sughrue, Theodore. Reviewed submitted version of manuscript: Preul, SafaviAbbasi, Sughrue, Theodore. Study supervision: Preul, Safavi-Abbasi, Hanel, Sughrue, Theodore. 


\section{Contributions of James Watson Kernohan}

\section{References}

1. Abbott KH, Kernohan JW: Primary sarcomas of the brain: review of the literature and report of twelve cases. Arch Neurol Psychiatry 50:43-66, 1943

2. Adler DE, Milhorat TH: The tentorial notch: anatomical variation, morphometric analysis, and classification in 100 human autopsy cases. J Neurosurg 96:1103-1112, 2002

3. Bailey OT: James W. Kernohan. J Neuropathol Exp Neurol 31:155-156, 1972

4. Bailey $\mathrm{P}$, Cushing H: Classification of the Tumours of the Glioma Group on a Histogenetic Basis with a Correlated Study of Prognosis. Philadelphia: JB Lippincott, 1926

5. Binder DK, Lyon R, Manley GT: Transcranial motor evoked potential recording in a case of Kernohan's notch syndrome: case report. Neurosurgery 54:999-1003, 2004

6. Collier J: The false localising signs of intracranial tumour. Brain 27:490-508, 1904

7. Corbin KB, Kernohan JW: Henry William Woltman, M.D., 1889-1964. Neurology 15:413-414, 1965

8. Dahlin DC: James Watson Kernohan: 1896-1981. Surg Neurol 21:107-109, 1984

9. Derakhshan I: The Kernohan-Woltman phenomenon and laterality of motor control: fresh analysis of data in the article "Incisura of the crus due to contralateral brain tumor." J Neurol Sci 287:296, 2009 (Letter)

10. Etienne D, Zurada A, Matusz P, Shoja MM, Tubbs RS, Loukas M: James Watson Kernohan (1896-1981): Frontiers in neuropathology. Clin Anat 25:527-529, 2012

11. Groeneveld A, Schaltenbrand G: Ein Fall von Duraendotheliom über der Grosshirnhemisphäre mit einer bemerkenswerten Komplikation: Läsion des gekreuzten Pes pedunculi durch Druck auf den Rand des Tentoriums. Dtsch Z Nervenheilkd 97:32-50, 1927

12. Haines DE, Lancon JA, Zubkov AY: James Watson Kernohan (1896-1981). J Neurol 252:1558-1559, 2005

13. Hussain SI, Cordero-Tumangday C, Goldenberg FD, Wollman R, Frank JI, Rosengart AJ: Brainstem ischemia in acute herniation syndrome. J Neurol Sci 268:190-192, 2008

14. Kernohan JW: Sarcomas of the brain. Ariz Med 20:169-171, 1963

15. Kernohan JW, Mabon RF, Svien HJ, Adson AW: A simplified classification of the gliomas. Proc Staff Meet Mayo Clin 24:71-75, 1949

16. Kernohan JW, Uihlein A: Sarcomas of the brain. Prog Clin Cancer 10:414-437, 1965

17. Kernohan JW, Woltman H: Incisura of the crus due to contralateral brain tumor. Arch Neurol Psychiatry 21:274, 1929

18. Kernohan JW, Woltman H: Incisura of the crus due to contralateral brain tumor. Proc Staff Meet Mayo Clin 3:69-70, 1928
19. Kernohan JW, Woltman HW, Adson AW: Gliomas of the cerebellopontine angle. J Neuropathol Exp Neurol 7:349-367, 1948

20. Kleihues P, Soylemezoglu F, Schäuble B, Scheithauer BW, Burger PC: Histopathology, classification, and grading of gliomas. Glia 15:211-221, 1995

21. Meyer A: Herniation of the brain. Arch Neurol Psychiatry 4: 387-400, 1920

22. Pearce JMS: Kernohan's notch. Eur Neurol 55:230-232, 2006

23. Perry A, Brat DJ: Practical Surgical Neuropathology: A Diagnostic Approach. Philadelphia: Churchill Livinstone, 2010

24. Ringertz N: Grading of gliomas. Acta Pathol Microbiol Scand 27:51-64, 1950

25. Sarkar A, Chiocca EA: Editorial. Multiple craniotomies. J Neurosurg 114:574-575, 2011

26. Sayre GP: In memoriam: James W. Kernohan, M.D. (18961981). J Neuropathol Exp Neurol 41:337-339, 1982

27. Schlotthauer CF, Kernohan JW: A glioma in a dog and a pinealoma in a silver fox (Vulpes fulvus). Am J Cancer 24:350356, 1935

28. Shelton BA, O'Hara E, Tubbs RS, Shoja MM, Barker FG, Cohen-Gadol AA: Emergency suboccipital decompression for respiratory arrest during supratentorial surgery: the untold story of a surgeon's courage in times of despair. Historical vignette. J Neurosurg 110:391-394, 2009

29. Sunderland S: The tentorial notch and complications produced by herniations of the brain through that aperture. Br J Surg 45:422-438, 1958

30. Svien HJ, Mabon RF, et al: A simplified classification of the gliomas, based on the concept of anaplasia. Surg Clin North Am 29:1169-1187, 1949

31. Wolf RFE, ter Weeme CA, Krikke AP: Kernohan's notch and misdiagnosis. Lancet 345:259-260, 1995

32. Yates AJ: An overview of principles for classifying brain tumors. Mol Chem Neuropathol 17:103-120, 1992

33. Yoo WK, Kim DS, Kwon YH, Jang SH: Kernohan's notch phenomenon demonstrated by diffusion tensor imaging and transcranial magnetic stimulation. J Neurol Neurosurg Psychiatry 79:1295-1297, 2008

Manuscript submitted December 16, 2013.

Accepted January 20, 2014.

Please include this information when citing this paper: DOI: 10.3171/2014.1.FOCUS13575.

Address correspondence to: Mark C. Preul, M.D., Neuroscience Publications, Barrow Neurological Institute, St. Joseph's Hospital and Medical Center, 350 W. Thomas Rd., Phoenix, AZ 85013. email: neuropub@dignityhealth.org. 